\title{
Two Extremely Low Birth Weight Infants Who Survived Functional Pulmonary Atresia with Normal Intracardiac Anatomy
}

\author{
Shuntaro Oka, MD ${ }^{1, \#}$ Utako Kondo, MD ${ }^{2, \#}$ Ayumi Oshima, MD ${ }^{1}$ Shun Matsumura, MD ${ }^{1}$ \\ Masayo Kanai, MD ${ }^{1}$ Akio Ishiguro, MD ${ }^{1}$ Yoichi Iwamoto, MD ${ }^{1}$ Hirotaka Ishido, MD ${ }^{1}$ \\ Isaku Omori, MD ${ }^{2}$ Satoshi Masutani, MD ${ }^{1}$ \\ ${ }^{1}$ Department of Pediatrics, Saitama Medical Center, Saitama Medical \\ University, Saitama, Japan \\ 2 Department of Neonatology, Tokyo Metropolitan Bokutoh Hospital, \\ Tokyo, Japan \\ Address for correspondence Satoshi Masutani, MD, Department of \\ Pediatrics and Pediatric Cardiology, Saitama Medical Center, Saitama \\ Medical University, 1981 Kamoda, Kawagoe-shi, Saitama 350-8550, \\ Japan (e-mail: masutani@saitama-med.ac.jp).
}

Am J Perinatol Rep 2019;9:e310-e314.

\author{
Abstract \\ Keywords \\ - functional pulmonary \\ atresia \\ - extremely low birth \\ weight infants \\ - preterm \\ - resistance \\ - prostaglandin \\ - acidosis
}

For the first time, we report about two extremely low birth weight infants who were born at 25 and 22 weeks' gestation and who survived functional pulmonary atresia (fPA) with normal intracardiac anatomy. A slow, reflected, and bimodal blood flow pattern in the pulmonary artery (both cases) and the presence of pulmonary regurgitation (1 case) were useful for diagnosing fPA. Timely use of lipo-prostaglandin E1 to maintain adequate pulmonary flow and reduce pulmonary arterial resistance and sodium bicarbonate to improve acidosis were effective treatments to attain forward flow. As optimal management is essential for the intact survival of extremely early preterm infants and the accurate diagnosis of fPA is difficult without the awareness of the disease entity, our cases underline the importance of recognizing that fPA can occur even in extremely low birth weight infants with normal intracardiac anatomy.
Functional pulmonary atresia (fPA) is a condition in which the pulmonary valve does not open during right ventricular systole despite the absence of morphological abnormality of the pulmonary valve. ${ }^{1}$ fPA rarely develops in infants with normal intracardiac anatomy. ${ }^{2}$ We report for the first time two extremely low birth weight infants born at 22 and 25 weeks' gestation, who survived such a condition. The two cases suggest the importance of recognizing fPA in infants admitted to the neonatal intensive care unit.

\section{Case Report}

\section{Case 1}

A male infant weighing $588 \mathrm{~g}$ was born at a gestational age of 25 weeks, 4 days without any specific information about

$\overline{\#}$ The first two authors equally contributed to this work. pulmonary flow on fetal screening echocardiography. He had Apgar scores of 1 and 6. Oligohydramnios and threatened premature labor were observed at 20 weeks' gestational age. Steroids were administered to his mother, and he was born via emergency cesarean delivery owing to complete premature membrane rupture. After intubation and surfactant administration, the patient underwent mechanical ventilation in the synchronized intermittent mandatory ventilation (SIMV) mode except for a transient trial of high frequency oscillation. His percutaneous arterial oxygen saturation $\left(\mathrm{SpO}_{2}\right)$ level in the right arm, measured using pulse oximetry, gradually decreased after 5 hours. At 9 hours, it further decreased to $\sim 80 \%$ even on a fraction of inspired oxygen $\left(\mathrm{FiO}_{2}\right)$ of $100 \%$ without a difference in $\mathrm{SpO}_{2}$ level between the upper and lower extremities. Echocardiography revealed moderate tricuspid regurgitation (TR) with a TR pressure gradient (TRPG) of $37 \mathrm{~mm} \mathrm{Hg}$, while his blood pressure was $45 \mathrm{~mm}$

Copyright $\odot 2019$ by Thieme Medical Publishers, Inc., 333 Seventh Avenue, New York, NY 10001, USA. Tel: +1(212) 584-4662.

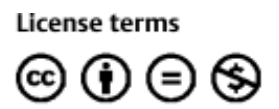

(c) $(1) \triangleq \$$ received

December 15, 2018 accepted after revision June 7, 2019
DOI https://doi.org/ 10.1055/s-0039-1697960. ISSN 2157-6998. 
$\mathrm{Hg}$. The right ventricular wall motion appeared visually unimpaired with $3 \mu \mathrm{g} / \mathrm{kg} / \mathrm{min}$ of dopamine and dobutamine infusion. The interatrial shunt was right-to-left, and no pulmonary arterial flow via the pulmonary vale was observed. Ductal flow was mainly with left-to-right shunt, and left pulmonary arterial flow was bimodal and extremely slow $(0.35 \mathrm{~m} / \mathrm{s}$; - Fig. 1A). We tentatively diagnosed pulmonary atresia (PA) with an intact ventricular septum. Soon after we initiated lipo-prostaglandin $\mathrm{E}_{1}\left(\mathrm{PGE}_{1}\right)$ to open the ductus arteriosus to maintain an adequate pulmonary flow, $\mathrm{SpO}_{2}$ dramatically increased to $98 \%$ in room air. Echocardiography revealed no opening of the pulmonary valve on day 1 (23 hours). However, on day 2 (47 hours), we observed reduced TR, left-to-right interatrial shunt, and blood flow from the right ventricle to the pulmonary artery. The left pulmonary arterial flow speed drastically increased $(0.95 \mathrm{~m} / \mathrm{s}$, - Fig. 1B). We finally diagnosed his condition as fPA. During fPA, the worst values of base excess and lactate were -8.2 and $2.77 \mathrm{mmol} / \mathrm{L}$, respectively. We reduced the $\mathrm{PGE}_{1}$ dose and discontinued $\mathrm{PGE}_{1}$ on day 3 (67 hours). We administered one dose of indomethacin $(0.1 \mathrm{mg} / \mathrm{kg})$ on day 3 ( 71 hours). Thereafter, pulmonary valvular motion and antegrade pulmonary arterial flow became well visible. After the closure of the ductus arteriosus on day 5, the pulmonary arterial flow was maintained. However, echocardiography on day 13 revealed the reopening of the ductus arteriosus. Although we administered indomethacin because of a symptomatic patent ductus arteriosus and severe bronchopulmonary dysplasia, it failed to close the ductus. Surgical ligation was required, which was successfully performed on day 20.
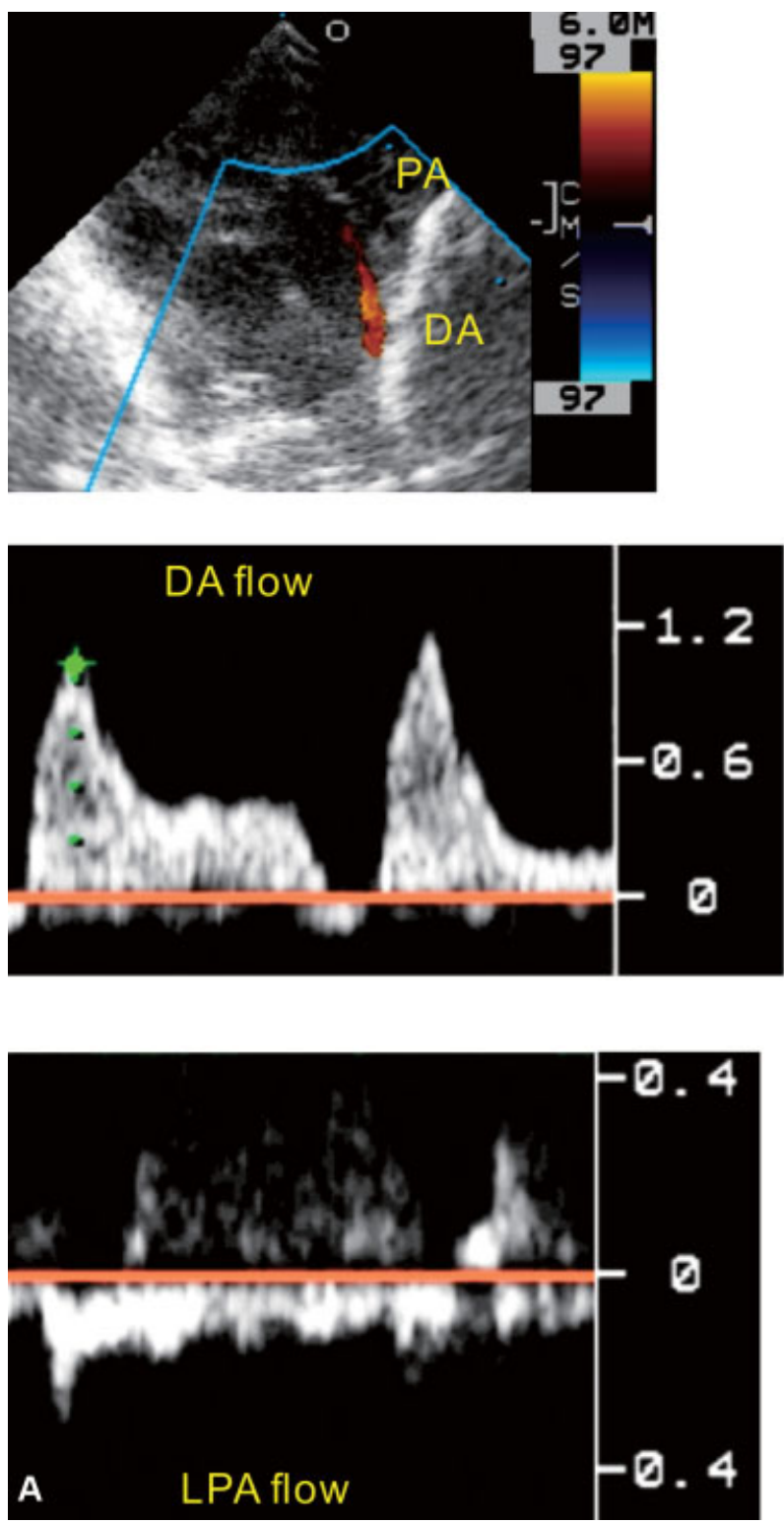
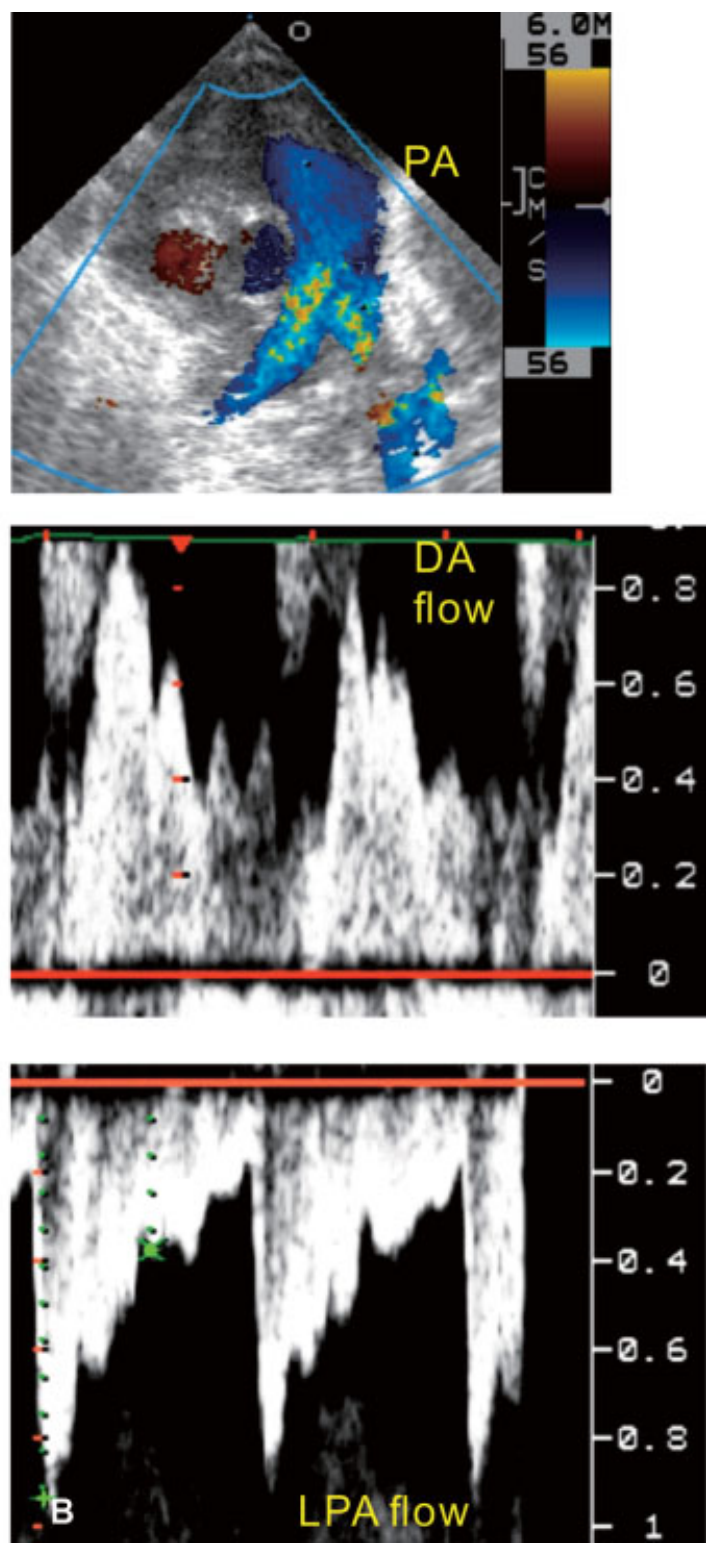

Fig. 1 Pulmonary and ductal flow patterns in case 1. (A) After birth (4 hours), the ductal flow was via a left-to-right shunt, but no right ventricular to pulmonary arterial flow was observed (upper panel). The ductal flow was characteristic (mid panel). The left pulmonary arterial flow was extremely slow $(0.3 \mathrm{~m} / \mathrm{s}$ ) and bimodal (lower panel). (B) Day 2 echocardiography (47 hours). Right ventricular to pulmonary arterial antegrade flow could be observed (upper panel). The ductal flow was increased (mid panel), and the peak systolic left pulmonary arterial flow velocity was greatly increased (1 m/s, lower panel). DA, ductus arteriosus; LPA, left pulmonary artery; PA, pulmonary artery. 


\section{Case 2}

A female infant weighing $582 \mathrm{~g}$ was born at a gestational age of 22 weeks, 1 day without any specific information about pulmonary flow on fetal screening echocardiography. She had Apgar scores of 4 and 6. She was born via emergent cesarean delivery due to premature membrane rupture and suspected intrauterine infection. After intubation and surfactant administration, the patient underwent mechanical ventilation in the SIMV mode, and the $\mathrm{SpO}_{2}$ level in her right arm remained at $\sim 80 \%$. Echocardiography revealed only mild dilation of the right heart, right-to-left interatrial shunt, and mild TR with a TRPG of $27 \mathrm{~mm} \mathrm{Hg}$ when the systolic blood pressure was $30 \mathrm{~mm} \mathrm{Hg}$. The pulmonary valve was not hypertrophic without doming, and its diameter was large enough ( $5 \mathrm{~mm}$; - Fig. 2A). However, we did not identify an apparent pulmonary valve opening during systole but found a trivial pulmonary regurgitation (-Fig. 2B). The main pulmonary arterial flow appeared as just a reflection of the ductal flow on color Doppler imaging (-Fig. 2A). The ductal flow was a bimodal left-to-right shunt (-Fig. 2C). The left pulmonary arterial flow was bimodal and slow $(0.42 \mathrm{~cm} / \mathrm{s}$, - Fig. $2 \mathrm{C})$, with each peak just after each ductal flow peak, indicating the reflected ductal shunt flow (-Fig. 2C).

Ten hours after birth, the ductus arteriosus was found to have been constricting with progressing hypoxemia $\left(\mathrm{SpO}_{2}\right.$ : $75-78 \%, \mathrm{FiO}_{2}$ : 0.5) and metabolic acidosis ( $\mathrm{pH} \mathrm{7.22-7.10).}$ Administrations of oxygen and nitric oxide were ineffective.
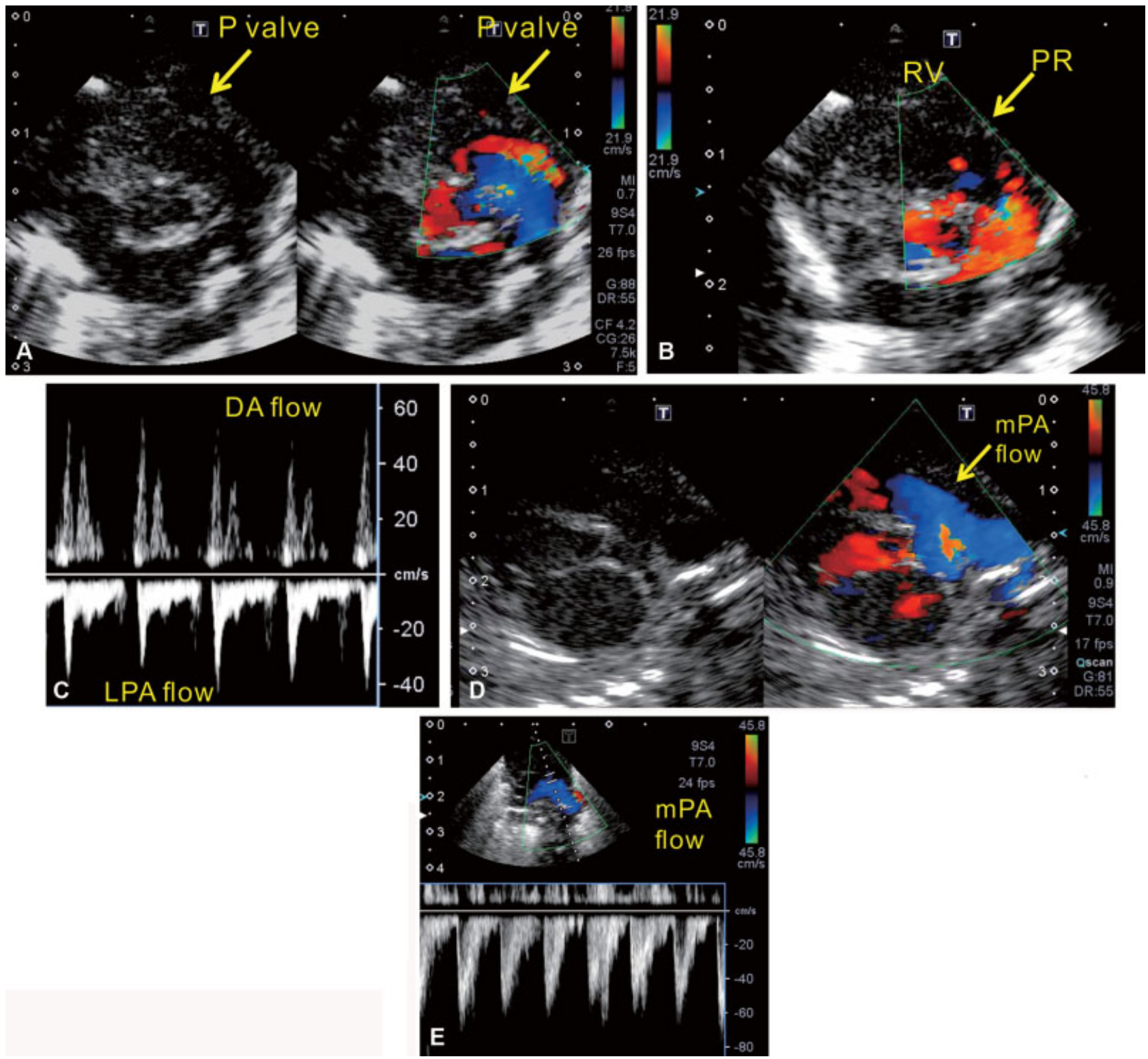

Fig. 2 Pulmonary and ductal flow patterns in case 2. A-C (day 0 ) and D-E (41 hours). (A) The pulmonary valve is not thick, but its opening is not visible. Ductal left-to-right shunt flow (red) is reflected at the pulmonary valve level (blue). (B) Trivial pulmonary regurgitation is present. (C) The left pulmonary arterial flow is extremely slow $(0.42 \mathrm{~m} / \mathrm{s})$ and bimodal with each peak soon after the ductal bimodal peak, indicating a ductussupplied pulmonary arterial flow. (D) At 41 hours, right ventricular to pulmonary arterial flow could be observed. (E) Pulsed wave Doppler showing a peak main pulmonary arterial velocity of $0.7 \mathrm{~m} / \mathrm{s}$. DA, ductus arteriosus; LPA, left pulmonary artery; P, pulmonary; PR, pulmonary regurgitation; RV, right ventricle. 
Because we still could not detect antegrade flow from the right ventricle to the pulmonary artery on echocardiography, we initiated PGE $_{1}$ to obtain sufficient pulmonary flow and increased dopamine and dobutamine dose each to $7 \mu \mathrm{g} / \mathrm{kg} / \mathrm{min}$ at 10 hours after birth. We also performed general management with volume loading and sodium bicarbonate to treat her metabolic acidosis. Echocardiography revealed no opening of the pulmonary valve at 26 hours after birth. However, at 41 hours after birth, we identified an opening of the pulmonary valve and an antegrade flow from the right ventricle to the pulmonary artery (-Fig. 2D, 2E); the flow direction at the foramen ovale was left-to-right with trivial TR. Right ventricular end-diastolic area increased from 84 to $102 \mathrm{~mm}^{2}$, and the fractional area change increased from 46 to $67 \%$. We completely excluded anatomical PA and fully diagnosed PPA and its recovery. During fPA, the worst values of base excess and lactate were -17.7 and $15.0 \mathrm{mmol} / \mathrm{L}$ at 14 hours after birth, respectively.

After we discontinued $\mathrm{PGE}_{1}$ and nitric oxide (at 41 and 54 hours after birth, respectively), her circulatory status remained stable with reduced trivial TR and left-to-right foramen ovale shunt. Thereafter, her ductus remained open and became hemodynamically symptomatic even after indomethacin administration on days 34,36 , and 37 . Surgical ligation was required, which was successfully performed on day 45 .

\section{Discussion}

To the best of our knowledge, our two patients are the first reported and survival cases of extremely low birth weight infants with fPA without heart disease. In very early preterm infants, appropriate circulatory management is essential for intact survival. ${ }^{3}$ However, without awareness of fPA, accurate diagnosis accompanies great difficulties. Thus, awareness of this disease entity is critically important for neonatal intensive care physicians. Our two cases provide important diagnostic and therapeutic implications.

The absence of right ventricle-to-pulmonary artery antegrade flow can be difficult to identify solely by color Doppler imaging. Even in PA, the main pulmonary blue-colored flow away from the pulmonary valve, although it is a reflection of ductal flow, can be observed on color Doppler imaging. However, pulsed wave Doppler signals of the pulmonary artery can provide useful information on the existence of PA; a low-speed bimodal flow pattern occurring just after a ductal shunt ( - Fig. $\mathbf{2 C}$ ) clearly indicates that the pulmonary flow is just a reflection of ductal flow, indicating PA.

fPA can also be difficult to differentiate from anatomical PA and severe pulmonary stenosis. The presence of pulmonary regurgitation excludes anatomical PA and can be an important clue for fPA. $^{4-6}$ However, lack of pulmonary regurgitation, like in case 1 in this report and previously reported cases, ${ }^{1}$ makes it more difficult to differentiate between PPA and membranous anatomical PA. If it is severe pulmonary valvular stenosis, the valve should be thick with doming and high-speed systolic antegrade jet on the center of the valve. Without these findings of stenosis, no pulmo- nary valve opening despite the presence of pulmonary regurgitation strongly indicates PPA as in case 2 in this report.

From physiological and therapeutic points of view, fPA can be considered as an ultimate right ventricular-pulmonary arterial afterload mismatch ${ }^{3}$ with zero antegrade stroke volume. When the pulmonary valve does not functionally open, the pulmonary arterial pressure is equal to the product of the pulmonary vascular resistance and flow supplied by the ductus arteriosus. If the right ventricle cannot generate a higher pressure than the pulmonary arterial pressure, the pulmonary valve will not open. In case 1 , prolonged oligohydramnios possibly caused the high pulmonary vascular resistance, which resulted in IPA despite the relatively high right ventricular pressure as evidenced by the TRPG of $37 \mathrm{~mm} \mathrm{Hg}$. $\mathrm{PGE}_{1}$, in this case, might help reduce pulmonary resistance ${ }^{7}$ and contribute to amelioration of the right ventricular and pulmonary arterial afterload mismatch, in addition to the open ductus arteriosus. In case 2, sodium bicarbonate to treat the acidosis appeared to be the most effective for improving fPA. Improvement in acidosis will help reduce pulmonary vascular resistance, ${ }^{8}$ increase left ventricular output, ${ }^{9}$ increase right ventricular preload and function, and reduce TR. Improvement in acidosis will contribute to the reduction in right ventricular afterload, increase in right ventricular systolic function, and correction of the right ventricular-pulmonary arterial afterload mismatch to enable opening of the pulmonary valve. As acidosis was a common finding between case 2 and previously reported fPA cases, ${ }^{1,2}$ acidosis seems an important risk factor and therapeutic target for PPA. Altogether, transient ventricular dysfunction after birth may play a central role in the development of fPA in these cases. Left ventricular function is transiently reduced after birth, ${ }^{3}$ probably because of losing the low-resistance placental circulation. Usually, the right ventricular function is not so affected because the pulmonary vascular resistance is reduced after birth. However, in cases with high pulmonary vascular resistance and/or a widely patent ductus arteriosus exposing the pulmonary vasculature to high systemic pressure, the right ventricular function can be transiently reduced similar to that of the left ventricle. Because the left ventricular output is approximately the preload of the right heart, its increase is a key element in overcoming the fPA status. Because amelioration of the transient ventricular dysfunction is an adaptation process of the postnatal circulation, some intervals between such therapies and the opening of the pulmonary valve would be needed.

Conversely, timely discontinuation of $\mathrm{PGE}_{1}$ is also important because of its potential side adverse effects. If the pulmonary flow via the ductus becomes too much under the condition of high pulmonary vascular resistance, the pulmonary arterial pressure may increase to a level that prevents the opening of the pulmonary valve. Furthermore, once the fPA is resolved, the ductus opening and shunt become useless and harmful because they might resist right ventricular antegrade output, and $\mathrm{PGE}_{1}$ can exert side effects such as apnea ${ }^{10}$ and may cause symptomatic patent ductus arteriosus. In fact, both our two cases later required surgical ductal closure, although we discontinued $\mathrm{PGE}_{1}$ after the recovery from fPA.

In conclusion, fPA can occur in extremely low birth weight infants without apparent congenital heart disease. Our cases 
suggest the importance of improving acidosis to enhance function and reduce afterload of the right ventricle, and timely initiation and discontinuation of $\mathrm{PGE}_{1}$ in extremely low birth weight infants with fPA.

Conflicts of Interest and Source of Funding

The authors have no conflicts of interest or sources of funding to disclose.

\section{Acknowledgments}

We thank all the physicians and medical staff who were involved in the treatment of the infants.

\section{References}

1 Altun G, Babaoğlu K, Binnetoğlu K, Kavas N, Arısoy AE. Functional pulmonary atresia in newborn with normal intracardiac anatomy: successful treatment with inhaled nitric oxide and pulmonary vasodilators. Ann Pediatr Cardiol 2013;6(01):83-86

2 Almeida-Filho OC, Schmidt A, Marin-Neto JA, Maciel BC. Functional pulmonary atresia in a newborn with normal intracardiac anatomy. Pediatr Cardiol 2002;23(06):647-649
3 Toyoshima K, Kawataki M, Ohyama M, et al. Tailor-made circulatory management based on the stress-velocity relationship in preterm infants. J Formos Med Assoc 2013;112(09):510-517

4 Freedon RM, Culham G, Moes F, Olley PM, Rowe RD. Differentiation of functional and structural pulmonary atresia: role of aortography. Am J Cardiol 1978;41(05):914-920

5 Lee CL, Hsieh KS, Huang TC, Lin CC, Choong CS. Recognition of functional pulmonary atresia by color Doppler echocardiography. Am J Cardiol 1999;83(06):987-988, A11

6 Lin MC, Chen CH, Fu YC, Jan SL. Functional pulmonary atresia: in a critically ill premature infant. Tex Heart Inst J 2010;37(04): 494-495

7 Kermode J, Butt W, Shann F. Comparison between prostaglandin E1 and epoprostenol (prostacyclin) in infants after heart surgery. Br Heart J 1991;66(02):175-178

8 Rudolph AM, Yuan S. Response of the pulmonary vasculature to hypoxia and $\mathrm{H}+$ ion concentration changes. JClin Invest 1966;45 (03):399-411

9 Fanconi S, Burger R, Ghelfi D, Uehlinger J, Arbenz U. Hemodynamic effects of sodium bicarbonate in critically ill neonates. Intensive Care Med 1993;19(02):65-69

10 Lim DS, Kulik TJ, Kim DW, Charpie JR, Crowley DC, Maher KO. Aminophylline for the prevention of apnea during prostaglandin E1 infusion. Pediatrics 2003;112(1 Pt 1):e27-e29 